\title{
Addressing Behavior in Collaborative Networks
}

\author{
Mahdieh Shadi and Hamideh Afsarmanesh \\ Federated Collaborative Networks Group, Informatics Institute, \\ Computer Science Department, University of Amsterdam \\ $\{$ m.shadi, h.afsarmanesh\} @uva.nl
}

\begin{abstract}
Many factors such as weak partner commitment, lack of proper partners' alignment on interest and values, individualism, lack of flexibility, and loss of autonomy may cause partnership's failures in collaborative networks. Most of these serious causes for conflicts in collaborative networks are rooted in partner's behavior, therefore analyzing and modeling the behavioral aspects of collaborative networks are important to enforce their success. This paper first addresses two kinds of behavior related to collaborative networks including Individual Collaborative Behavior and Network Collective Behavior, and then introduces an approach to measure the comparative individual collaborative behavior of partners in networks.
\end{abstract}

Keywords: Collaborative Networks, Individual Collaborative Behavior, Collective Behavior, Causal Reasoning.

\section{Introduction}

With advances in communication and information technology, today organizations can interact and communicate with each other and exchange sensitive information without the traditional limitations of time and location. Collaborative networks, such as global supply chains, support industries to manufacture and deliver products to markets with the required speed and efficiency. A CN (collaborative Network) is an alliance constituting a variety of entities (e.g. organizations and people) that are largely autonomous, geographically distributed, and heterogeneous in terms of their operating environment, culture, social capital, and goals, and that cooperate and collaborate to better achieve common or compatible goals, and whose interactions are supported by the computer network [1],[2].

In general, each organization (or person) involved in a collaborative partnership works and interacts with other members to achieve common or compatible goals. During this interaction partners expose various behaviors, according to the situations in which they are involved. This kind of behavior is called Individual Collaborative Behavior, regarding to how one behaves within a $\mathrm{CN}$. If it were possible to analyze, model and predict the organizations' behaviors, many conflicts and difficulties in CNs could have been resolved and ultimate productivity of individuals at the CNs would have been drastically improved [3]. Another kind of behavior related to CNs is the Network Collective Behavior which shows the behavior of a group of partners, as a whole. Effective Network Collective Behavior leads to improved CN productivity and 
higher quality, thus more customer satisfaction, as well as more profit and more power for the CNs.

Inspired by the modeling frameworks introduced earlier in the literature related to collaborations and network aspects [4] and considering the complexity of CNs, the ARCON (A Reference model for Collaborative Networks) modeling framework is developed. This framework divides the CNs complexity into a number of perspectives. Its environment characteristics perspective includes two subspaces that cover the internal elements characteristics of CNs, labeled as "Endogenous Elements (Endo-E)", as well as the external interactions characteristics, labeled as "Exogenous Interaction (Exo-I)", that address the logical surrounding of the CNs. The Endo-E subspace consists of four perspectives, as follows: Structural dimension, Componential dimension, Functional dimension and Behavioral dimension [5],[6]. Among these four, the behavioral dimension is the least studied in the research on CNs. However, there are some base applicable research related to human behavior and agent behavior. In [7], the authors show the feasibility of soft control on collaborative behavior of a group by a case study. In [8], a new attempt for modeling and simulation of group behavior in e-government organizations is provided and also [9] presents a qualitative simulation method for analyzing employee group behavior by integrating QSIM (Qualitative SIMulation) with basic causal reasoning. Moreover, some issues such as the small world phenomenon, clustering and power relationships from the area of Social Networks Analysis (SNA) may contribute to this topic. For example, in [10], some indicators related to promote the fairness and transparency are proposed. Some Other indicators, such as reliability, responsiveness, flexibility, etc. are defined in the SCORE model [11] known throughout industrial branches. Standardizing processes within a supply chain because of making the process comparable and compatible is the goal of this model and these indicators are used to measure the performance of organization in supply chains.

This paper is organized as follows: in section 2, the individual collaborative behavior and a new approach to measure the comparative individual collaborative behavior are addressed. In section 3 the Network Collective Behavior is discussed, and finally in section 4 some conclusive remarks are drawn.

\section{Individual Collaborative Behavior}

The principles, policies, and governance rules that either drive or constrain the behavior of the $\mathrm{CN}$ and its member over time, are addressed in behavioral dimension of the ARCON reference model [5]. This may include elements such as honesty and integrity, trust, openness, well performance, professionalism, mutual respect, commitment to network, code of ethics and IPR policy. Considering these governance rules and some other related factors, it is possible to introduce an approach for measurement of comparative individual behavior. Below, we first discuss the importance of the individual collaborative behavior (in section 2.1) and then we explain our approach to model it (in section 2.2). 


\subsection{The Role of Individual Collaborative Behavior in CNs}

Due to the impressive number of both human and organizational behavioral factors found in the analyzed reports, an assumption can be made that probably most partnership failures and successes are strongly related to, if not caused by, the behavioral factors of the involved partners [3]. Good communication, decision by consensus, creativity, fairness, flexibility, best use of interests, knowledge sharing, joy in working together, visible leadership, readiness, open and honest participation, willingness to commit resources and capabilities, development of social skills, transparency in provision of information are behavioral factors leading partnership's success.

Moreover, partners' behavioral factors have a vital influence on their collaboration readiness and establishing trust relationship with other partners, while individual collaborative behavior can be motivated through creation of incentives and rewarding models and mechanisms as a part of CN's governance model.

Analyzing the behavior of a CN's members is therefore necessary. Obviously, the purpose of modeling and analyzing the individual behavior may target specific objectives. These objectives may include identification or prediction of conflicts, selecting the best-fit members to create a new VO, better role and right assignment in CNs, effective membership structure management, and general measuring of individual collaborative behavior in networks.

\subsection{Measuring the Comparative Individual Behavior}

Modeling and analyzing behavior of $\mathrm{CN}$ partners involve different sets of characteristics, and depends on the perspective for which the behavior is considered. Therefore, it is better to consider some perspectives for each of above mentioned objectives.

As such, behavior for a $\mathrm{CN}$ partner cannot be represented by an absolute value; rather it can be measured for instance regarding a specific purpose against the behavior of other $\mathrm{CN}$ partners. Mechanisms can be defined to assess the individual behavior of a $\mathrm{CN}$ partner in comparison to others. For this purpose, every perspective can be characterized by a set of traits / actions. Also, specific metrics (variables that can be measured) and constraints shall be specified for each trait/action.

For example, when a VO planner wants to select a VBE member as a partner for a $\mathrm{VO}$, different aspects of the past individual behavior of that member can be compared with others, according to different perspectives as exemplified by three perspectives presented in table1.

Furthermore, in order to assess the individual behavior, inter-relation among different traits/actions should be studied and well understood. In this work, causal relationships among different traits/actions are used to represent how they influence each other. To present this approach, consider the first perspective in Table1, conforming to past $\mathrm{VO}$ regulations. A causal diagram for this example is shown in Figure 1. In this causal diagram, the plus sign (+) indicates that the increase or decrease of the first factor causes the increase or decrease of the second factor, while the minus sign (-) indicates that the increase or decrease of the first factor causes the decrease or increase of the second factor [12]. 
Table 1. Perspectives, traits and metrics for partner selection objective

\begin{tabular}{|c|c|c|c|}
\hline Perspectives & \multicolumn{2}{|c|}{ Traits/Actions } & Metrics \\
\hline \multirow{13}{*}{$\begin{array}{l}\text { Conforming } \\
\text { to past VO } \\
\text { Regulations } \\
\quad(\mathrm{CR})\end{array}$} & \multicolumn{2}{|c|}{ Punctuality } & $\begin{array}{l}\text { e.g. average hours/days of delay in } \\
\text { product delivery }\end{array}$ \\
\hline & \multicolumn{2}{|c|}{ Pro-activity } & $\begin{array}{l}\text { e.g. number of articles published in the } \\
\text { press, number of new recommended } \\
\text { members, and number of awards won }\end{array}$ \\
\hline & \multicolumn{2}{|c|}{ Flexibility } & $\begin{array}{l}\text { e.g. average period of time (in hours or } \\
\text { days) to develop or change a new } \\
\text { logistic process and percentage of time } \\
\text { without process faults }\end{array}$ \\
\hline & \multicolumn{2}{|c|}{ Responsiveness } & $\begin{array}{l}\text { e.g. average response time to emails } \\
\text { (in hours or days) }\end{array}$ \\
\hline & \multicolumn{2}{|c|}{ Responsibility } & $\begin{array}{l}\text { e.g. number of successful collaboration } \\
\text { involved, number of responsibilities or } \\
\text { roles accepted in past experiences }\end{array}$ \\
\hline & \multicolumn{2}{|c|}{ Innovation } & $\begin{array}{l}\text { e.g. average number of industrial } \\
\text { patents per year in last five years }\end{array}$ \\
\hline & \multirow[t]{6}{*}{$\begin{array}{c}\text { Keeping } \\
\text { commitment }\end{array}$} & $\begin{array}{l}\text { Problem/co } \\
\text { nflict } \\
\text { resolution }\end{array}$ & $\begin{array}{l}\text { e.g. number of problems that escalated } \\
\text { to VO management }\end{array}$ \\
\hline & & $\begin{array}{l}\text { Willingness } \\
\text { to adapt }\end{array}$ & $\begin{array}{l}\text { e.g. percentage of accepted adaptations } \\
\text { to new required plans }\end{array}$ \\
\hline & & $\begin{array}{c}\text { Willingness } \\
\text { to } \\
\text { compensate }\end{array}$ & $\begin{array}{l}\text { e.g. difference between delay in input } \\
\text { and delay in output }\end{array}$ \\
\hline & & $\begin{array}{l}\text { providing } \\
\text { impulses }\end{array}$ & $\begin{array}{l}\text { e.g. number of suggestions realized for } \\
\text { improvements }\end{array}$ \\
\hline & & $\begin{array}{c}\text { Problem } \\
\text { avoidance }\end{array}$ & $\begin{array}{l}\text { e.g. provided reaction time (in hours or } \\
\text { days) when critical status is reported }\end{array}$ \\
\hline & & Cooperation & $\begin{array}{l}\text { e.g. number of contacts with other } \mathrm{VO} \\
\text { members }\end{array}$ \\
\hline & \multicolumn{2}{|c|}{ Trustworthiness } & $\begin{array}{l}\text { e.g. number of tasks successfully } \\
\text { completed }\end{array}$ \\
\hline \multirow{2}{*}{$\begin{array}{l}\text { Value Adding } \\
\text { to past VOs } \\
\text { (VA) }\end{array}$} & \multicolumn{2}{|c|}{ Sharing assets } & $\begin{array}{l}\text { e.g. number of different assets which a } \\
\text { member shares in a VO }\end{array}$ \\
\hline & \multicolumn{2}{|c|}{ Reputation } & $\begin{array}{l}\text { e.g. number of Years in business, } \\
\text { number of customers, size of market }\end{array}$ \\
\hline \multirow{5}{*}{$\begin{array}{l}\text { Special } \\
\text { collaborative } \\
\text { business } \\
\text { Traits (ST) }\end{array}$} & \multicolumn{2}{|c|}{ Being Fair } & $\begin{array}{l}\text { e.g. number of disagreement on } \\
\text { benefits distribution, either against the } \\
\text { original contract, or against the } \\
\text { consortion majority }\end{array}$ \\
\hline & \multicolumn{2}{|c|}{ Reuse of existing results } & $\begin{array}{l}\text { e.g. number of use and provision of } \\
\text { references to other member's } \\
\text { articles/results }\end{array}$ \\
\hline & \multicolumn{2}{|c|}{ Tolerance to stress } & $\begin{array}{l}\text { e.g. number of times pulling out of } \\
\text { commitment }\end{array}$ \\
\hline & \multicolumn{2}{|c|}{ Being courageous } & $\begin{array}{ll}\text { e.g. number of administration roles } \\
\text { accepted, number of risks taken }\end{array}$ \\
\hline & \multicolumn{2}{|c|}{ Information sharing } & $\begin{array}{l}\text { e.g. frequency of information provision } \\
\text { to other collaborators }\end{array}$ \\
\hline
\end{tabular}




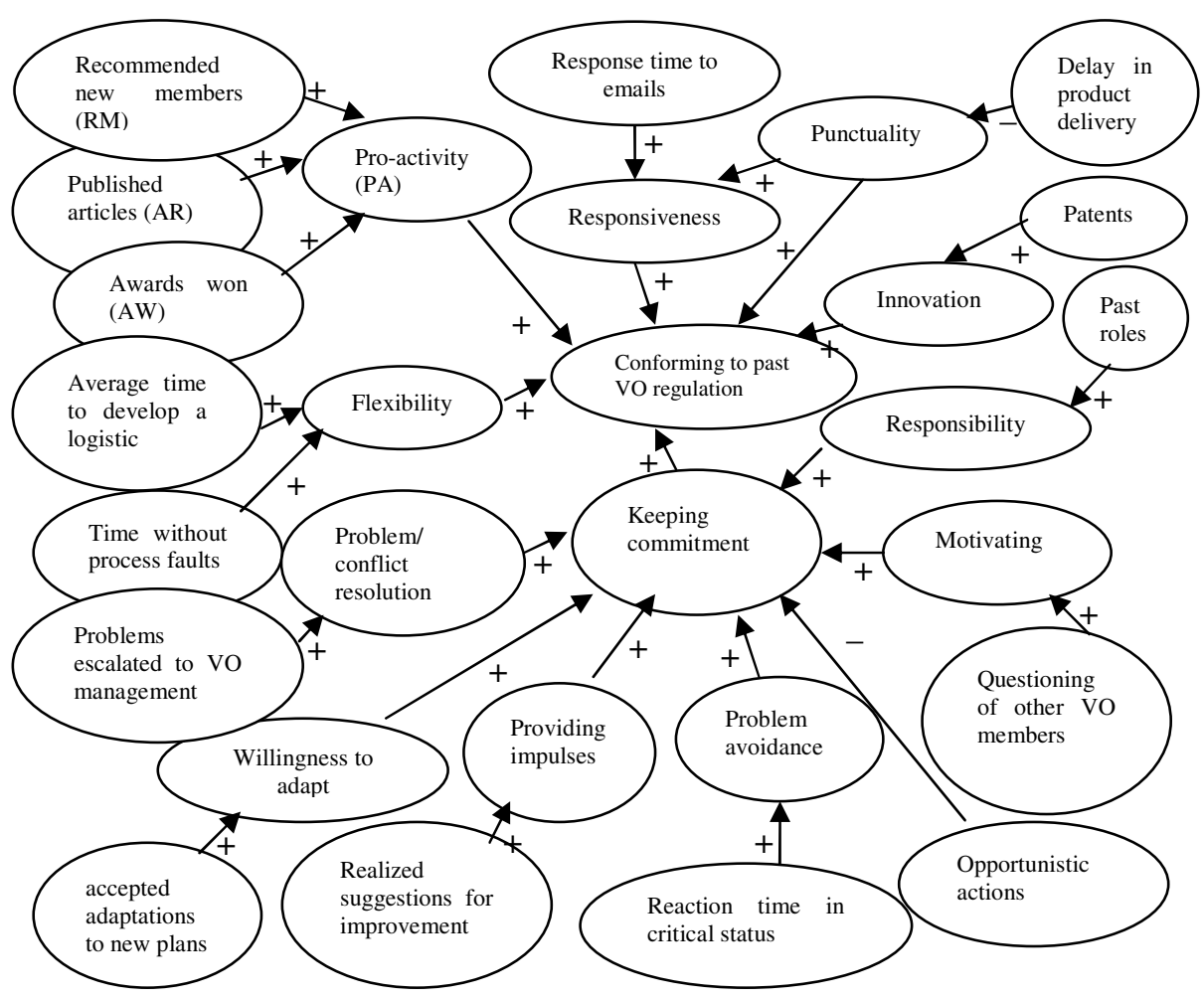

Fig. 1. Quantitative analysis of relations among trait/actions using causal diagram

Causal effects in Figure 1 represent the relations among different traits/actions in form of mathematical equations. By reasoning on the base of these causal relationships, some mathematical formulas can be derived to calculate values for comparative individual behavior of $\mathrm{CN}$ members. The plus sign (+) in the causal diagram represents either addition or multiplication, and the minus sign (-) represents subtraction or division depending on the metrics that are related to the traits/actions. The selection of the correct arithmetic operator depends on the metrics that scales it and the balance of dimensions [13], [14]. For example, for measuring the rate of proactivity (PA), it is needed to add the number of recommended new members (RM), number of articles in press (AR) and number of awards won (AW) as equation 1 shows:

$$
P A=R M+A R+A W .
$$

The derivative of equation (1) represents the rate of change of each of the factor with respect to time and the relations among the changes, as illustrated in equation 2 . The integration of equation 2 provides the accumulation of PA, which represents the total rate of pro-activity for a period of time $t_{1}$ to $t_{2}$ (equation 3 ). 


$$
\begin{gathered}
\frac{d}{d t} P A=\frac{d}{d t} R M+\frac{d}{d t} A R+\frac{d}{d t} A W . \\
\int_{t_{1}}^{t_{2}} \frac{d}{d t} P A=\int_{t_{1}}^{t_{2}} \frac{d}{d t} R M \int_{t_{1}}^{t_{2}} \frac{d}{d t} A R+\int_{t_{1}}^{t_{2}} \frac{d}{d t} A W .
\end{gathered}
$$

The rates of change as well as the accumulations equation for all factors in Figure 1 can be considered in the same way (according to their relationships). After that, there is a formula for measuring the rate of Conforming to past VO Regulations (CR). Also, it can be done for the other two mentioned perspectives in Table1 (VA and ST). Consequently, to calculate the final comparative behavior score for suitable partner selection objective, we should compute an average of weighted scores of all perspectives, as equation 4 illustrates:

$$
\text { Score }=\text { average }\left(W_{1} \times C R+W_{2} \times V A+W_{3} \times S T\right) .
$$

The weights $\left(W_{1}, W_{2}, W_{3}\right)$ shall be defined by experts in the field, depending on the specific type of VO to be established. These weights should belong to the $[0,1]$ interval and the sum of all these weights should be equal to 1 . Finally, since we calculate the score for each member in the VBE, when a VO planner decides to select a most suitable member, she/he can compare how they rate against each other.

\section{Network Collective Behavior}

Analyzing and modeling the Network Collective Behavior which refers to how a group behaves as a whole and the factors which influence it, is more complex than individual behavior. In fact, modeling collective behavior involves contributions from multiple disciplines.

Mechanisms, such as incentives and rewards, assessing of alignment of values and approach applied to the governance of a $\mathrm{CN}$ are factors affecting Network Collective Behavior of the $\mathrm{CN}$. These factors are discussed respectively in the following paragraphs.

Incentives and rewards mechanisms may result in changes in the behavior of a $\mathrm{CN}$. Networking sustainability through fair and transparent distribution of benefits, and addressing contributors' expectations are objectives of theses mechanisms. The basis of the incentive system is on the motivation that a $\mathrm{CN}$ convinces its participants to be pro-active in relation to business opportunities.

The individual and Network Collective Behavior in a $\mathrm{CN}$ are influenced by the value system of network members. Therefore, it is important to identify the value system of the networks and their individual members to have an improved collaborative process. A CN consists of independent and autonomous entities which each of them has its own value system. Many conflicts among partners might come up because of misalignment of values. In the absence of identical value systems, the members' perceptions of the results of the collaboration processes may be different and consequently, they may show some non-collaborative behaviors, such as unwillingness to share knowledge and other inter-organizational disagreements [15]. 
CN Governance includes some structures, principles and rules for resources allocation and rights assignment. Moreover, it supervises the entities and activities within a CN. Governance and the behavioral aspects influence each other, mutually. The constraining rules of $\mathrm{CN}$ governance may lead changes in collective and individual behavior of network members, and also behavioral aspects such as character of a CN member influence the CN's governance.

For modeling the Network Collective Behavior, it is needed to identify the objectives, perspectives, traits/actions and metrics such as presented for modeling the individual collaborative behavior in the previous section. In this case, objectives may include improving: customer satisfaction, benefits to $\mathrm{CN}, \mathrm{CN}$ achieving more power in the market/society. These objectives can be considered according to the two perspectives: financial and social perspectives.

\section{Conclusion}

Quantitative causal modeling is a powerful aid to understand and enable practical decisions about what might be the best action to take in a certain circumstance. Therefore, in our approach we measure the comparative individual collaborative behavior by using quantitative causal modeling. This approach could lead to identify or predict conflicts, select the best-fit VO members, assign the roles and rights in CNs more effectively, and measure the individual collaborative behavior in networks. Analyzing and improving the individual collaborative behavior of $\mathrm{CN}$ members will influence the Collective Behavior of the CN. According to our approach, partners' behavior could be compared with each other, and partners will be informed that enhancing their individual behavior will result in more success in their collaboration. As such, improving the individual behavior through factors such as incentives and rewards as well as alignment of values and fairness in governance rules are proposed to influence the network's collective behavior.

\section{References}

1. Camarinha-Matos, L.M., Afsarmanesh, H.: Collaborative networks: Value creation in a knowledge society. In: Knowledge Enterprise: Intelligent Strategies in Product Design, Manufacturing and Management, pp. 26-40. Springer, Heidelberg (2006)

2. Afsarmanesh, H., Ermilova, E., Msanjila, S.S., Camarinha-Matos, L.M.: Modeling and Management of Information Supporting Functional Dimension of Collaborative Networks. In: Hameurlain, A., Küng, J., Wagner, R. (eds.) Transactions on Large-Scale Data- and Knowledge-Centered Systems I. LNCS, vol. 5740, pp. 1-37. Springer, Heidelberg (2009)

3. Rosas, J.: Assessing organizations collaboration readiness, a behavioral approach. PhD thesis (2009)

4. Camarinha-Matos, L.M., Afsarmanesh, H.: A comprehensive modeling framework for collaborative networked organizations. The Journal of Intelligent Manufacturing 18(5), 527-615 (2007)

5. Camarinha-Matos, L., Afsarmanesh, H.: On reference models for collaborative networked organizations. International Journal of Production Research 46(9), 2453-2469 (2008) 
6. Afsarmanesh, H., Camarinha-Matos, L.M.: The ARCON modeling framework. In: Collaborative Networks Reference Modeling, pp. 67-82. Springer, Heidelberg (2008)

7. Han, J., Li, M., Guo, L.: Soft control on Network Collective Behavior of a group of autonomous agents by a shill agent. Jrl. Syst. Sci. \& Complexity, 54-62 (2006)

8. Wu, J., Hu, B.: Modeling and simulation of group behavior in e-government implementation. In: Proceeding of the 2007 Winter Simulation Conference, pp. 1284-1291 (2007)

9. Hu, B., Gongcheng, X.: Integrated Description and qualitative simulation method for group behavior. Journal of Artificial Societies and Social Simulation 8(2) (2005)

10. Abreu, A.: A contribution to the development of a theory for collaborative networks. PhD Thesis, New University of Lisbon (2007)

11. Beamon, B.M.: Measuring supply chain performance. International Journal of Operations and Production Management 19(3), 275-292 (1999)

12. Pearl, J.: Causality Models Reasoning, and Inference. Cambridge University Press, Cambridge (2000)

13. Krikwood, C.W.: System Dynamics Method. Ventana System Inc. (1998)

14. Ge, Y., Yang, J.B., Proudlove, N., Spring, M.: System dynamics modeling for supply-chain management. The International Transactions in Operational Research 11, 495-509 (2004)

15. Camarinha-Matos, L.M., Macedo, P.: Towards A Conceptual Model Of Value Systems In Collaborative Networks. Virtual Enterprises and Collaborative Networks, 53-64 (2007) 